\title{
Normal endothelial function
}

Volume 3 Issue 4 - 2015

\section{Mini review}

Endothelium is a monolayer of cells covering the inner surface of blood vessels, and it acts as a functional and structural barrier between bloods and the vessel wall, preventing platelet and leukocyte adhesion and aggregation, controlling permeability to plasma components, and modulating blood flow. The healthy endothelium is a dynamic organ that regulates vascular tone by balancing production of vasodilators and vasoconstrictors in response to a variety of stimuli. ${ }^{1}$ Nitric oxide (NO), the predominant mediator of normal vascular function, is released by the endothelium and diffuses within the vessel wall, causing smooth muscle dilation and myofibrillar relaxation in response to stimulation by endogenous factors such as bradykinin, acetylcholine, and catecholamine, as well as ischemia, temperature change, and mechanical stimuli, including shear stress. ${ }^{2}$ Endothelium also provides anti-proliferative and anti-inflammatory actions, and regulates fibrinolysis as well as the coagulation pathway through the balanced production of anticoagulant (e.g. tissue plasminogen activator, thrombomodulin) and pro-coagulant (e.g., tissue factor, von Willebrand factor) factors, which maintain haemostatic properties of blood vessels. ${ }^{3}$

\section{Central role of NO}

NO is synthesized from L-arginine by NO synthase (NOS) ${ }^{4}$ The 3 main NOS isoforms including constitutive endothelial NOS (eNOS or NOS3), neuronal NOS (or NOS1), and inducible NOS (iNOS) that are differently coexpressed in NO-producing cells and also inducible by immunological stimuli. ${ }^{5}$ Although NO produced by all 3 pathways regulates normal physiology, large amounts of NO produced by iNOS may have acytotoxic effect and inhibit myocardial contractility. ${ }^{6}$ Because HF triggers changes in myocardial NO production, shifting from spatially and temporally regulated NO production by eNOS to excessive release by iNOS, the distinction between NO produced by eNOS/neuronal NOS or iNOS is important. ${ }^{7,8}$ In the intact endothelium, hormonal and physical stimuli cause the constitutively expressed eNOS to generate NO, which then diffuses into smooth muscle cells and stimulates soluble guanylate cyclase (sGC) to produce cyclic guanine monophosphate, which causes smooth muscle relaxation and also has antiproliferative effects. In addition to these smooth muscle cell mediated vascular effects, NO targets neighboring extra vascular tissues, including myocardium. ${ }^{9}$ Release of endothelial progenitor cells from bone marrow, which has been shown to repair damaged endothelium, is also partially NO dependent. ${ }^{10}$ Furthermore, $\mathrm{NO}$ can act as an endocrine vaso-regulator, modulating blood flow in the microcirculation when vehiculated by $\mathrm{S}$ nitroso-hemoglobin, which transports and releases NO to areas of tissue hypoxia or increased oxygen extraction. ${ }^{11}$ Importantly, disruption of NO delivery to the microcirculation contributes to vasoconstriction and uncoupling of oxygen delivery in skeletal muscle. Given the pivotal role of NO in mediating endothelial function, impairment of vasodilation due to decreased NO availability is often used as a measure of endothelial function. ${ }^{12,13}$

\section{Endothelial dysfunction in HF}

Although endothelial dysfunction has traditionally been associated with systemic vasoconstriction in advanced HF, newer insights

\author{
Hesham Khalid Rashid Mousa \\ Department of Cardiology Medicine, Benha university, Egypt
}

Correspondence: Hesham Khalid Rashid Mousa, Department of Cardiology Medicine, Benha university, Egypt, Tel 20482578334,Email hesham_mosa2001@yahoo.com

Received: March 25, 2015 | Published: October 12, 2015

suggest a more central role in HF pathogenesis. ${ }^{14,15}$ The failing heart is characterized by an altered redox state with over production of reactive oxygen species, and there is increasing evidence to suggest that the abnormal cardiac and vascular phenotypes characterizing the failing heart are caused in large part by imbalances between NO bioavailability and oxidative stress. ${ }^{16} \mathrm{In} \mathrm{HF}$, neurohumoral activation, release of inflammatory messengers from the myocardium, and altered local shear forces modulate gene expression and promote atherogenesis, increasing oxidative stress and reducing production of NO. ${ }^{17,18}$

The resulting endothelial dysfunction triggers an increase in the production of cytokines, down-regulation or uncoupling of eNOS, ${ }^{19,20}$ and further increases in oxidative stress. ${ }^{21,22}$ These processes culminate in reduced NO bioavailability and worsening endothelial dysfunction, which in turn propagates development and progression of HF. ${ }^{23-26}$ These abnormalities have emerged as a common pathophysiological element in the development and progression of $\mathrm{HF}$ and are also associated with HF risk factors. ${ }^{27}$ Within this construct, myocardial adverse effects and endothelial dysfunction related to oxidative stress represent a unifying feature that drives both the symptoms and unfavorable outcomes associated with both ischemic and nonischemic. $^{28}$

\section{Acknowledgments}

None.

\section{Conflicts of interest}

Author declares there are no conflicts of interest.

\section{References}

1. Furchgott RF, Zawadzki JV. The obligatory role of endothelial cells in the relaxation of arterial smooth muscle by acetylcholine. Nature. 1980;288(5789):373-376. 
2. Rubanyi GM, Romero JC, Vanhoutte PM. Flow-induced release of endothelium-derived relaxing factor. Am J Physiol. 1986;250(6 Pt 2):H1145-149.

3. Libby P, Aikawa M, Jain MK. Vascular endothelium and atherosclerosis. Handb Exp Pharmacol . 2006;(176 Pt 2):285-306.

4. Moncada S, Palmer RM, Higgs EA. Nitric oxide: physiology, pathophysiology, and pharmacology. Pharmacol Rev. 1991;43(2):109-142.

5. Lüscher TF, Barton M. Biology of the endothelium. Clin Cardiol 1997;20(11 Suppl 2):II3-10.

6. Ikeda U, Shimada K. Nitric oxide and cardiac failure. Clin Cardiol. 1997;20(10):837-841.

7. Agnoletti L, Curello S, Bachetti T, et al. Serum from patients with severe heart failure down regulates eNOS and is proapoptotic: role of tumor necrosis factor-alpha. Circulation. 1999; 100(19):1983-1991.

8. Smith CJ, Sun D, Hoegler C, et al. Reduced gene expression of vascular endothelial NO synthase and cyclooxygenase-1 in heart failure. Circ Res. 1996;78:58-64.

9. Paulus WJ, Bronzwaer JG. Nitric oxide's role in the heart: control of beating or breathing? Am J Physiol Heart Circ Physiol. 2004;287(1):H8-13.

10. Aicher A, Heeschen C, Mildner-Rihm C, et al. Essential role of endothelial nitric oxide synthase for mobilization of stem and progenitor cells. Nat Med. 2003;9(11):1370-1376.

11. Datta B, Tufnell-Barrett T, Bleasdale RA, et al. Red blood cell nitric oxide as an endocrine vasoregulator: a potential role in congestive heart failure. Circulation. 2004;109(11):1339-1342.

12. Celermajer DS, Sorensen KE, Gooch VM, et al. Non-invasive detection of endothelial dysfunction in children and adults at risk of atherosclerosis. Lancet. 1992;340:1111-1115.

13. Corretti MC, Anderson TJ, Benjamin EJ, et al. Guidelines for the ultrasound assessment of endothelial-dependent flow-mediated vasodilation of the brachial artery: a report of the International Brachial Artery Reactivity Task Force. J Am Coll Cardiol. 2002;39(2):257-265.

14. Drexler H, Hayoz D, Munzel T, et al. Endothelial function in chronic congestive heart failure. Am J Cardiol. 1992;69(19):1596-1601.

15. Kubo SH, Rector TS, Bank AJ, et al. Endothelium-dependent vasodilation is attenuated in patients with heart failure. Circulation. 1991;84(4):1589-1596.
16. Parodi O, De Maria R, Roubina E. Redox state, oxidative stress and endothelial dysfunction in heart failure: the puzzle of nitrate-thiol interaction. J Cardiovasc Med (Hagerstown). 2007;8(10):765-774.

17. Tousoulis D, Charakida M, Stefanadis C. Inflammation and endothelial dysfunction as therapeutic targets in patients with heart failure. Int $J$ Cardiol. 2005;100(3):347-353.

18. Drexler H. Endothelium as a therapeutic target in heart failure Circulation. 1998;98:2652-2655.

19. Bank AJ, Lee PC, Kubo SH. Endothelial dysfunction in patients with heart failure: relationship to disease severity. $J$ Card Fail. 2000;6(1):29-36

20. Katz SD, Khan T, Zeballos GA, et al. Decreased activity of the L-arginine-nitric oxide metabolic pathway in patients with congestive heart failure. Circulation. 1999;99(16):2113-2117.

21. Hare JM, Stamler JS. NO/redox disequilibrium in the failing heart and cardiovascular system. J Clin Invest. 2005;115(3):509-517.

22. Ontkean M, Gay R, Greenberg B. Diminished endothelium-derived relaxing factor activity in an experimental model of chronic heart failure. Circ Res . 1991;69(4):1088-1096

23. Vanhoutte PM, Shimokawa H, Tang EH, et al. Endothelial dysfunction and vascular disease. Acta Physiol (Oxf). 2009;196(2):193-222.

24. Munzel T, Harrison DG. Increased superoxide in heart failure: abiochemical baroreflex gone awry. Circulation. 1999;100(3):216-218.

25. Bauersachs J, Bouloumie A, Fraccarollo D, et al. Endothelial dysfunction in chronic myocardial infarction despite increased vascular endothelial nitric oxide synthase and soluble guanylate cyclase expression: role of enhanced vascular superoxide production. Circulation. 1999;100(3):292-298.

26. Vita JA. Endothelial function and clinical outcome. Heart. 2005;91(10):1278-1279.

27. Davignon J, Ganz P. Role of endothelial dysfunction in atherosclerosis Circulation. 2004;109(23 Suppl 1):III27-32.

28. Bauersachs J, Widder JD. Endothelial dysfunction in HF. Pharmacol Rep. 2008;60(1):119-126. 